Paidéia, 2006, 16(33), 51-58

\title{
HABILIDADES DE LEITURA DE PRÉ-ESCOLARES DEFICIENTES AUDITIVOS: LETRAMENTO EMERGENTE ${ }^{1}$
}

\author{
Heloísa Helena Motta Bandini \\ Claudia Lessa de Azevedo Corrêa de Oliveira* \\ Érika Costa de Souza* \\ Faculdade de Fonoaudiologia de Alagoas/ UNCISAL
}

\begin{abstract}
Resumo: O letramento emergente é um conjunto de comportamentos e conhecimentos sobre leitura e escrita que acontecem no período entre o nascimento e a fase onde a criança torna-se capaz de escrever e ler de maneira convencional. O presente estudo tem como objetivo verificar o desenvolvimento do letramento emergente por meio da escala de letramento emergente em crianças portadoras de deficiência auditiva de grau severo a profundo ou profundo usuárias de LIBRAS (Língua Brasileira de Sinais). O estudo foi dividido em duas avaliações com a aplicação da Escala de Letramento Emergente em momentos diferentes, ao longo de um ano. Fizeram parte desse estudo crianças entre 6.5 anos e 7.3 anos, deficientes auditivas com perda bilateral de grau severo a profundo ou profundo, usuárias de LIBRAS. Os resultados do estudo indicam que o desenvolvimento de habilidades dessa população é semelhante ao de crianças ouvintes.
\end{abstract}

Palavras-chave: Surdez; Perda auditiva; Linguagem; Leitura.

\section{LITERACY ABILITIES OF PRESCHOOL DEAF CHILDREN:EMERGENT LITERACY}

Abstract: Emerging literacy is composed by behaviors and knowledge on reading and writing which take place from birth up to child's of reading and writing conversationally. It has been considered to be an important requisite for reading and writing accomplishments. This study objectives to verify emerging literacy knowledge level among severe-to-deep deaf children, who use Brazilian Signal Language (BSL). This study was divided up into two evaluations using the emergent literacy test in distinct moments during one year period. Eight BSL severe-to-deep bilateral deaf children took place in this study (6.5 to 7.3 years old). Results suggested emergent literacy accomplishiment in our study group is the same of that among normal children.

Key words: language; reading; hearing less; deafness.

Introdução: Cerca de noventa por cento das crianças surdas são filhas de pais ouvintes (Sacks, 1998); além de invisível nos primeiros meses de vida a surdez também não é um fator esperado quando os pais são ouvintes e a gestação transcorreu tranqüila. Desta forma, mesmo pais dedicados e experientes muitas vezes demoram muito tempo para perceber que seu filho não escuta.

\footnotetext{
${ }^{1}$ Artigo recebido em 12/01/2006 e aceito para publicação em 03/ 05/2006.

${ }^{2}$ Endereço para Correspondência: Heloisa Helena Motta Bandini, Fundação Universitária de Ciências da Saúde de Alagoas Governador Lamenha Filho, Faculdade de Fonoaudiologia de Alagoas - Ambulatório de Aparelhos de Amplificação Sonora Individual Prof Alfredo Dacal, Rua Jorge de Lima,113, Trapiche da Barra Maceió- Al, CEP: 57010-300, E-mail: hbandini@superig.com.br

* Bolsistas de iniciação científica pela Fundação de Amparo a Pesquisa de Alagoas - FAPEAL processo 005/04.
}

O isolamento lingüístico causado pela deficiência auditiva é o maior de todos os riscos que corre um bebê que nasce surdo, pois a criança perde informações importantes que quase sempre resultam em um atraso no desenvolvimento de linguagem. O diagnóstico tardio e as dificuldades em iniciar um tratamento adequado podem comprometer todo o desenvolvimento da criança deixando clara, portanto, a importância do diagnóstico e do início de processo de intervenção precoce.

Com relação ao processo de intervenção Katz (1999) coloca que há três tendências mundiais sobre o assunto. A primeira é a educação oral que defende que as crianças deficientes auditivas devem utilizar a audição residual, a leitura orofacial e a fala para se comunicarem. A segunda é a comunicação total, em 
que a criança utiliza o método oral combinado com uso de sinais, soletração digital e/ou qualquer outra abordagem que facilite a comunicação. A terceira é a utilização das Línguas Nacionais de Sinais, como a Americana (ASL) ou a Brasileira (LIBRAS).

Muitas pessoas equivocadamente afirmam que as línguas de sinais são pobres quanto a sua estrutura. Esta concepção é oriunda do fato de que as línguas de sinais não apresentam, por exemplo, elementos de ligação (tais como preposições e conjunções). Todavia, se se compreender as línguas de sinais como sendo naturais, isto é, línguas que compartilham uma série de características específicas que as distinguem dos demais sistemas de comunicação e ao mesmo tempo como um sistema abstrato de regras finitas, capaz de gerar um número ilimitado de construções que permitem a comunicação entre seus usuários, pode-se compreender que a complexidade das línguas de sinais é apenas diferente da das línguas orais. A aparente carência de elementos de ligação, como preposições e conjunções, por exemplo, é destruída quando se entende que nestas línguas tais elementos são incorporados na estrutura dos sinais por meio de relações espaciais, estabelecidas pelo movimento ou outros recursos lingüísticos (Quadros \& Karnopp, 2004).

Assim, pode-se verificar que o uso de uma língua, mesmo que na modalidade viso-espacial, confere ao indivíduo o acesso a todos os recursos que a linguagem pode proporcionar, isto é, a organização do pensamento, a capacidade de lidar com coisas e fatos mesmo à distância, a habilidade de abstrair e manusear símbolos e finalmente de se comunicar com outras pessoas, estabelecendo uma vida social e política sem restrições.

Limongi (2003) diz que para que ocorra um desenvolvimento apropriado do individuo é necessário que este faça parte de uma cultura, construa valores e sinta-se como pertencendo a um grupo que reflete sua identidade. O uso de uma língua comum entre pessoas portadoras de características singulares, no caso a deficiência auditiva para o surdo, torna-se $o$ agente aglutinador da comunidade e confere ao indivíduo identidade. Estas características tornam as línguas de sinais, no caso do Brasil a LIBRAS, como natural dos surdos e o aprendizado dela ocorre em período análogo à aquisição de uma língua oral pelas crianças ouvintes, desde que o sujeito seja exposto a ela.

Segundo Williams (2004), a interação social promovida pelo uso de uma língua é fundamental para o desenvolvimento da leitura e da escrita, tornando este processo mais natural e menos difícil de ser adquirido. Ciasca, Capellini e Tonelotto (2003) referem que a atividade de leitura e escrita é uma das mais difíceis de ser realizada pelo ser humano, pois envolve processos lingüísticos, anatômicos e neuropsicológicos altamente complexos.

A literatura tem mostrado que o domínio de uma língua, quer na modalidade oral que na modalidade viso espacial, é fundamental para a aquisição de letramento emergente e este por sua vez é um forte pré-requisito para a aquisição de leitura e escrita.

De acordo com Sulzby e Teale (1991), o letramento emergente é um conjunto de habilidades prévias de leitura e escrita, adquiridas pela criança no período compreendido entre o nascimento e a idade em que ela aprende a ler e escrever de forma convencional. Williams (2004) fala que o letramento emergente seria um termo comumente usado para representar o encontro inicial de jovens crianças com a leitura e a escrita.

A pesquisa sobre letramento emergente baseiase em dois referenciais: um Piagetiano e outro Vygostskiniano. O primeiro tem o foco dos estudos voltado para como a criança constrói seus conceitos sobre leitura e escrita. Essa perspectiva enfatiza como os conceitos da criança são concebidos, como se modificam e o quanto eles diferem dos dos adultos. O segundo focaliza o papel da interação social entre o adulto e a criança para desenvolvimento dos conhecimentos iniciais sobre leitura e escrita. (Sulzby \& Teale, 1991).

Dentro destes referenciais todo o comportamento relativo a materiais escritos apresentado por uma criança é interpretado como uma forma de aproximação à leitura convencional e o contato com materiais escritos mediado por adultos pode favorecer que ela, ainda jovem, tome conhecimento do mundo letrado (Katims,1994; Rego 1985; Sulzby 1985; Sulzby \& Teale,1991).

Luria (1988) em um estudo realizado em 1928, cujo objetivo foi evidenciar a apreensão do caráter 
simbólico da escrita pelas crianças, verificou que para atingi-la elas percorrem um longo caminho iniciado com rabiscos indiferenciados até chegar aos signos. O estudo foi realizado com crianças ouvintes de quatro a nove anos de idade que não sabiam escrever e concluiu que em uma fase inicial do processo de aquisição de linguagem escrita elas se relacionam com a escrita sem saber seu significado, apenas imitando o adulto.

De acordo com Rottenberg (2001) crianças deficientes auditivas profundas passam pelas mesmas etapas que as ouvintes no processo de aquisição de leitura e escrita, ou seja, apresentam representações simbólicas, desenhos, rabiscos, reconhecimento dos formatos das letras para enfim chegar à forma convencional. Para este autor as línguas de sinais podem ser o suporte para a criança com deficiência aprender a ler e escrever; ele verificou ainda que as oportunidades para que uma criança surda pré-escolar possa explorar livros e materiais escritos em casa e na escola são tão essenciais para o desenvolvimento de leitura e escrita quanto o são para as ouvintes.

Entender como uma criança deficiente auditiva aprende a ler e escrever de forma bem sucedida é importante por dois aspectos: um seria porque ao entender este processo de aquisição e desenvolvimento da leitura e da escrita torna mais fácil favorecê-lo e outro, porque esta é uma forma potencial de informação sobre leitura em todas as populações.

Este estudo teve como objetivo verificar o desenvolvimento do letramento emergente por meio da escala de letramento emergente em crianças portadoras de deficiência auditiva de grau severo a profundo ou profundo, usuárias de LIBRAS (Língua Brasileira de Sinais).

\section{Método}

\section{Participantes}

Fizeram parte do estudo 07 crianças portadoras de deficiência auditiva neurossensorial bilateral de grau severo a profundo ou profundo de etiologia congênita, e idades entre 6.5 e 7.3 anos, com média de 6.8 anos, provenientes de classe social baixa ${ }^{1}$, filhas de pais analfabetos e /ou com baixa escolaridade ${ }^{2}$.
Cinco crianças já apresentavam diagnóstico de perda auditiva concluído no início do estudo; as duas restantes tiveram o diagnóstico de perda auditiva concluído ao ingressarem no estudo. Para todas as crianças o diagnóstico foi considerado concluído após a realização de avaliação audiológica completa composta de dois exames, a Audiometria Tonal Limiar (ATL) e a Imitânciometria, e/ou Potenciais Auditivos Evocados de Tronco Cerebral (ABR).

As crianças freqüentavam uma única sala de Educação Infantil, no ensino público do Estado, destinada às crianças surdas, sendo a professora ouvinte e fluente em LIBRAS, e tendo, duas vezes por semana aulas de LIBRAS, ministradas por uma instrutora surda, para as crianças e uma vez por semana as aulas de LIBRAS para os pais das crianças.

No início do estudo, cinco crianças usavam Aparelhos de Amplificação Sonora Individual (AASI) bilateralmente e duas desconheciam esse dispositivo. Em maio de 2005 as duas crianças restantes passaram por um processo de seleção e adaptação de AASIs. Todas freqüentavam terapia fonoaudiológica uma vez por semana com sessões de 30 minutos, em unidades públicas de saúde auditiva.

As atividades em sala de aula estavam relacionadas ao processo de alfabetização em Língua Portuguesa, que consistiam, em geral, na correspondência entre o alfabeto digital /o impresso /figuras, bem como a instrução formal da LIBRAS.

De acordo com os relatos da professora, todas as crianças ao iniciarem as atividades escolares apresentavam apenas gestos próprios, indicativos e usados para expressar suas necessidades básicas. O ensino de uma língua começou na escola 16 meses antes do início deste estudo, sendo assim, as crianças apresentavam 16 e 21 meses de exposição formal a LIBRAS para a primeira e segunda avaliação, res-

\footnotetext{
${ }^{1}$ Embora não tenha sido aplicado qualquer tipo de avaliação social padronizada, todas as famílias participantes do estudo recebiam auxilio do Programa Bolsa Família do Governo Federal ou eram beneficiadas pela Lei Orgânica de Assistência Social (LOAS). Para participar de ambos os programas a renda familiar per capita deve ser inferior a $\mathrm{R} \$ 75,00$ (setenta e cinco Reais) mensais.

${ }^{2}$ A escolaridade dos pais foi verificada informalmente quando da assinatura do Termo de Consentimento Livre e Esclarecido; apenas duas mães assinaram o termo, os outros expressaram sua anuência a pesquisa usando as impressões digitais.
} 
pectivamente. Com relação à escrita, elas não tinham seu uso formal no início do estudo.

\section{Materiais}

\section{Escala de letramento emergente}

Foi utilizada a Escala de Letramento Emergente proposta por Saint-Laurent, Giasson e Couture (1998). Embora essa escala apresente alguns itens em que a atribuição de pontos seja subjetiva, isto é, de acordo com a interpretação do avaliador, ela tem sido utilizada em trabalhos na área por abranger vários aspectos do Letramento Emergente, por ser lúdica, de fácil aplicação e especialmente por utilizar atividades cotidianas da criança, evitando assim problemas com a execução da tarefa.

O total máximo de pontos da escala é de 53 pontos; o item 5 (orientação à leitura) foi excluído da avaliação diante da impossibilidade da criança surda usuária de LIBRAS acompanhar a história narrada em sinais e em sua forma escrita ao mesmo tempo, uma vez que as duas habilidades são visuais e não podem ser realizadas de forma concomitante. Assim, o total máximo de pontos a ser obtido era de 50 pontos.

Para garantir a fidedignidade da coleta de dados, esta foi realizada com a presença de dois observadores independentes da avaliadora e feitos os cálculos de fidedignidade. escala:

O Quadro a seguir traz os itens avaliados pela

\begin{tabular}{|l|l|}
\hline Itens & Pontuação \\
\hline $\begin{array}{l}\text { 1) Interesse por livros - A pesquisadora apresen- } \\
\text { tou diferentes livros para a criança e observou } \\
\text { as suas reações. Os pontos foram atribuídos } \\
\text { diante do seguinte critério: } 0 \text { - nenhum interes- } \\
\text { se; } 1 \text { = precisou de incentivo para olhar o livro; } \\
2 \text { = foi encorajada a pegar os livros e } 3 \text { = pegou } \\
\text { os livros espontaneamente e olhou para eles. }\end{array}$ & \\
\hline 2) Interesse pela história lida - Uma história foi \\
contada para a criança em LIBRAS e foi aplica- \\
da uma medida de interesse que varia de $0=$ sem \\
interesse, 1= pouco interesse, $2=$ interesse com $).$ \\
interrupções do foco de atenção e 3 = interesse \\
contínuo.
\end{tabular}

\begin{tabular}{|c|c|}
\hline $\begin{array}{l}\text { sobre a própria história; respostas às questões do } \\
\text { avaliador que exigiam predições sobre o texto; fra- } \\
\text { ses do texto e conexões com coisas já conhecidas. } \\
\text { Esses comportamentos foram medidos em uma es- } \\
\text { cala de pontos que variava de } 0=\text { nenhuma participa- } \\
\text { ção, } 1=\text { pouca participação, } 2=\text { participação quando } \\
\text { solicitada e } 3=\text { alta participação. }\end{array}$ & \\
\hline $\begin{array}{l}\text { 4) Capacidade de manusear o livro - A pontuação foi } \\
\text { atribuída de acordo com os seguintes critérios: } 1 \\
\text { ponto para o livro segurado com o lado certo para } \\
\text { cima; } 1 \text { ponto para o livro segurado com a capa para } \\
\text { frente, três pontos para as páginas viradas uma a } \\
\text { uma, } 2 \text { = mais que a metade das páginas viradas e } \\
\text { apenas } 1=\text { poucas viradas uma a uma. }\end{array}$ & $\begin{array}{l}(1+1+3=5 \\
\text { pontos }) .\end{array}$ \\
\hline $\begin{array}{l}\text { 5) Orientação na leitura - Pedia-se à criança que seguis- } \\
\text { se o texto com o dedo enquanto o mesmo era lido } \\
\text { para ela. O critério de pontuação foi de um ponto } \\
\text { quando apontou o começo do texto, um ponto quan- } \\
\text { do se voltou para a outra linha e um ponto se voltou } \\
\text { para o fim do texto. }\end{array}$ & $\begin{array}{l}\text { (tarefa } \\
\text { excluída) }\end{array}$ \\
\hline $\begin{array}{l}\text { 6) Conceitos sobre escrita - Durante a leitura de um } \\
\text { texto, em três diferentes ocasiões, foi solicitado à } \\
\text { criança que fizesse um círculo ao redor de uma letra, } \\
\text { de uma palavra e de uma frase. Foi atribuído um } \\
\text { ponto para a resposta correta. }\end{array}$ & (0-1 ponto). \\
\hline $\begin{array}{l}\text { 7) Relação entre palavra falada e palavra escrita - Três } \\
\text { frases curtas eram sinalizadas para a criança, esta por } \\
\text { sua vez deveria apontar qual a frase sinalizada entre } \\
\text { as suas formas impressas. Foi atribuído um ponto } \\
\text { para a resposta correta. }\end{array}$ & (0-1 ponto). \\
\hline $\begin{array}{l}\text { 8) Funções da escrita-Foram apresentadas para a crian- } \\
\text { ça dez figuras e esta deveria identificar quais que } \\
\text { continham escrita. }\end{array}$ & (0-10 pontos). \\
\hline $\begin{array}{l}\text { 9) Leitura da escrita do ambiente - Foram apresentados } \\
\text { para a criança diversos rótulos, marcas e palavras } \\
\text { comuns no ambiente. A criança deveria identificar } \\
\text { dez delas. Foi atribuído um ponto para cada respos- } \\
\text { ta correta. }\end{array}$ & (0-10 pontos). \\
\hline $\begin{array}{l}\text { 10) Reconhecimento do primeiro nome - Quatro pa- } \\
\text { lavras foram apresentadas para a criança, em uma } \\
\text { folha de Papel A4, escritas com letra de imprensa, } \\
\text { entre elas o próprio nome da criança, que ela deve- } \\
\text { ria identificar. Foi atribuído um ponto pela res- } \\
\text { posta correta. }\end{array}$ & (0-1 ponto). \\
\hline $\begin{array}{l}\text { 11) Leitura de faz-de-conta - Após ver uma história } \\
\text { sinalizada pela pesquisadora a criança foi solicita- } \\
\text { da a ler a história em LIBRAS. Os pontos são } \\
\text { atribuídos da seguinte forma: } 1 \text { = quando a crian- } \\
\text { ça classificou e comentou os itens de figuras dife- } \\
\text { rentes; } 2 \text { = quando construiu em sinais uma expo- } \\
\text { sição seqüencial das figuras; } 3 \text { = quando criou } \\
\text { uma a história com ênfase semelhante à da língua } \\
\text { escrita; } 4 \text { = quando fez uso de escrita de maneira } \\
\text { pré-convencional para ler a história; } 5 \text { = quando } \\
\text { leu a história convencionalmente. }\end{array}$ & (0-5 pontos) \\
\hline
\end{tabular}




\begin{tabular}{|l|l|}
\hline 12) Escrita - A criança foi solicitada a escre- & (0-6 pontos $)$ \\
ver seu nome e uma palavra simples, cons- & \\
tituída de sílabas do tipo consoante vogal, & \\
tais como caneta, sapato, bola, menino. & \\
Cada produção foi avaliada em duas dimen- & \\
sões: caligrafia e princípio alfabético. Para & \\
caligrafia, os pontos foram atribuídos da & \\
seguinte forma: $1=$ desenho; $2=$ rabisco & \\
ondulado; $3=$ rabisco parecido com letra; 4 & \\
= unidades parecidas com letras; $5=$ letras e & \\
6 = escrita convencional. Para a descoberta & \\
do princípio alfabético foram criadas três & \\
categorias de pontuação: $0=$ nenhuma evi- & \\
dência de princípio alfabético; $1=$ alguma & \\
evidência de princípio alfabético e $2=$ pa- & \\
drão. & \\
\hline
\end{tabular}

Seleção dos livros:Foram utilizados livros contendo dois tipos de histórias infantis: clássicas, tais como "Os Três Porquinhos”, "Chapeuzinho vermelho" e outras desconhecidas, tais como, "O Cãozinho viralata” Todos os livros apresentavam o mesmo tipo de figura e pertenciam à coleção Fabulas de Ouro, Editora Novo Tempo.

\section{Procedimentos de coleta de dados.}

Para a caracterização do repertório de letramento emergente foram aplicadas duas avaliações em dois diferentes momentos: outubro de 2004, março de 2005. As sessões de avaliação ocorreram semanalmente no horário de aula e as crianças eram avaliadas individualmente em uma sala cedida pela escola para a realização do estudo.

Foram apresentados livros de histórias infantis pela pesquisadora, para as crianças de forma individual, utilizando LIBRAS como forma de comunicação, observando a reação de cada uma diante do material.

\section{Resultados e Discussão}

Os resultados relacionados às habilidades de letramento emergente foram avaliados de acordo com o escore total alcançado pelas crianças nas duas investigações.

A Figura 1 traz os dados das crianças no total da escala.

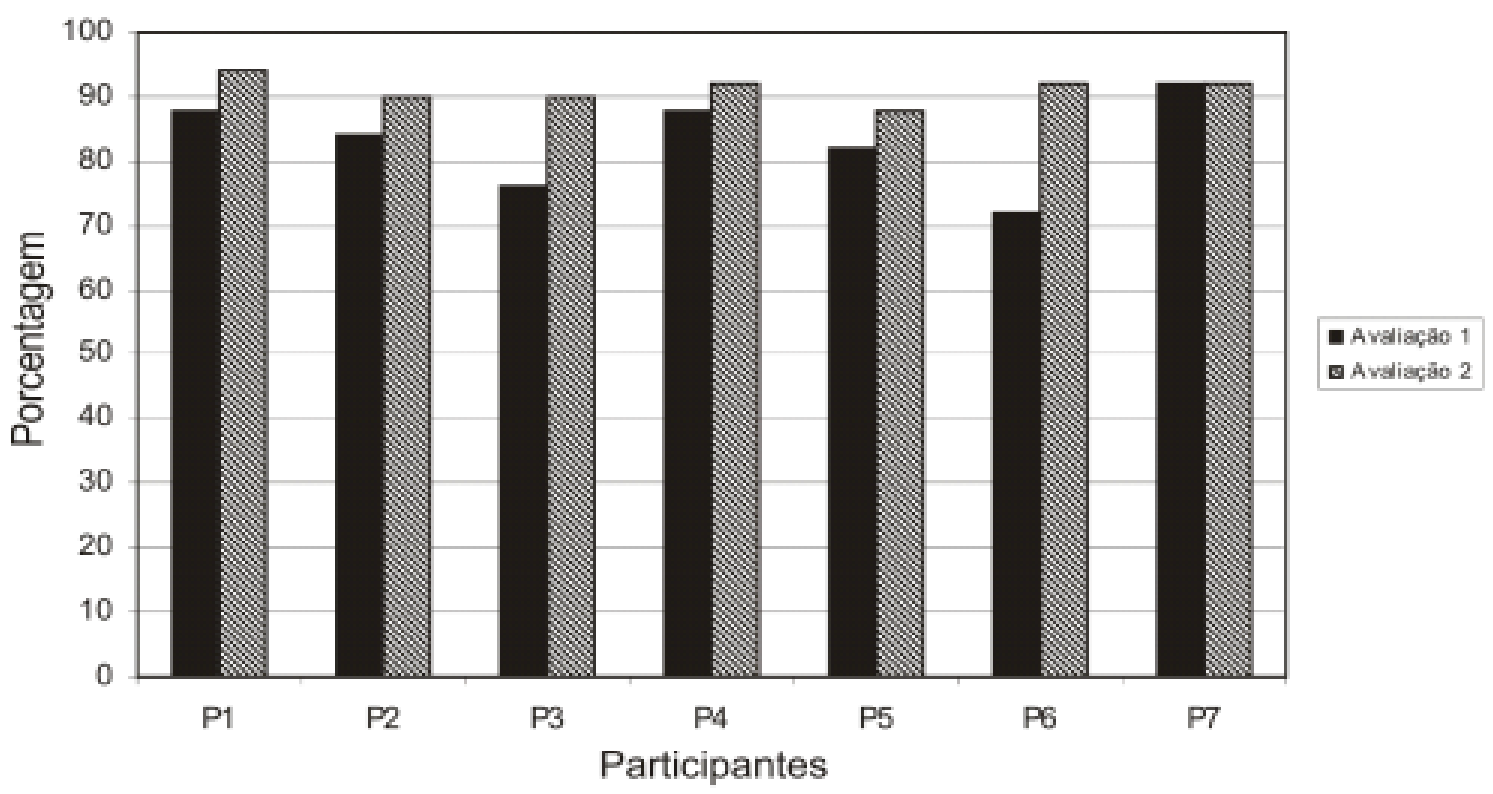

Figura 1 -Resultados da Escala de Letramento Emergente para a primeira e a segunda avaliação.

Como se pode observar os escores totais são discretamente melhores para todos os participantes do estudo na segunda avaliação. Os participantes P3 e P6 mostram uma melhora relevante tendo em apenas dois meses atingido 90\% das habilidades neces- sárias para a aquisição de uma língua escrita. Isto se deve provavelmente à exposição a material escrito e ao contato com a língua escrita, propiciados pelo ambiente escolar. 
De acordo com Willians (1994) e Rottenberg (2001), mesmo crianças surdas quando expostas a uma língua e a material letrado têm comportamentos de futuros leitores. Este fato sugere que investimentos em programas de Educação Infantil dentro de uma perspectiva escolar voltada para o contato com material letrado podem ser efetivos em auxiliar crianças surdas usuárias de LIBRAS a verem-se como futuros leitores e escritores, e facilitar o processo de aquisição de leitura e escrita, mesmo quando elas são provenientes de classes sociais mais baixas, filhas de pais semi alfabetizados.

Esta habilidade de domínio do letramento emergente torna-se ainda mais interessante se observada do ponto de vista da evolução das crianças. Em, ape- nas seis meses de trabalho decorridos entre a primeira e a segunda avaliação, observa-se um crescimento expressivo no domínio das habilidades de letramento emergente, em especial para o P6.

A escala de letramento emergente oferece ainda uma breve avaliação do conceito de escrita apresentado pelas crianças sob dois aspectos: caligrafia, isto é, se elas utilizam ou não letras convencionais e principio alfabético, ou seja, se domina a relação letra-som (Ferreiro \& Teberosky,1986).

Os dados encontrados a respeito de caligrafia e do uso do princípio alfabético, para a primeira e segunda avaliação, podem ser observados nas figuras 2 e 3 , respectivamente.

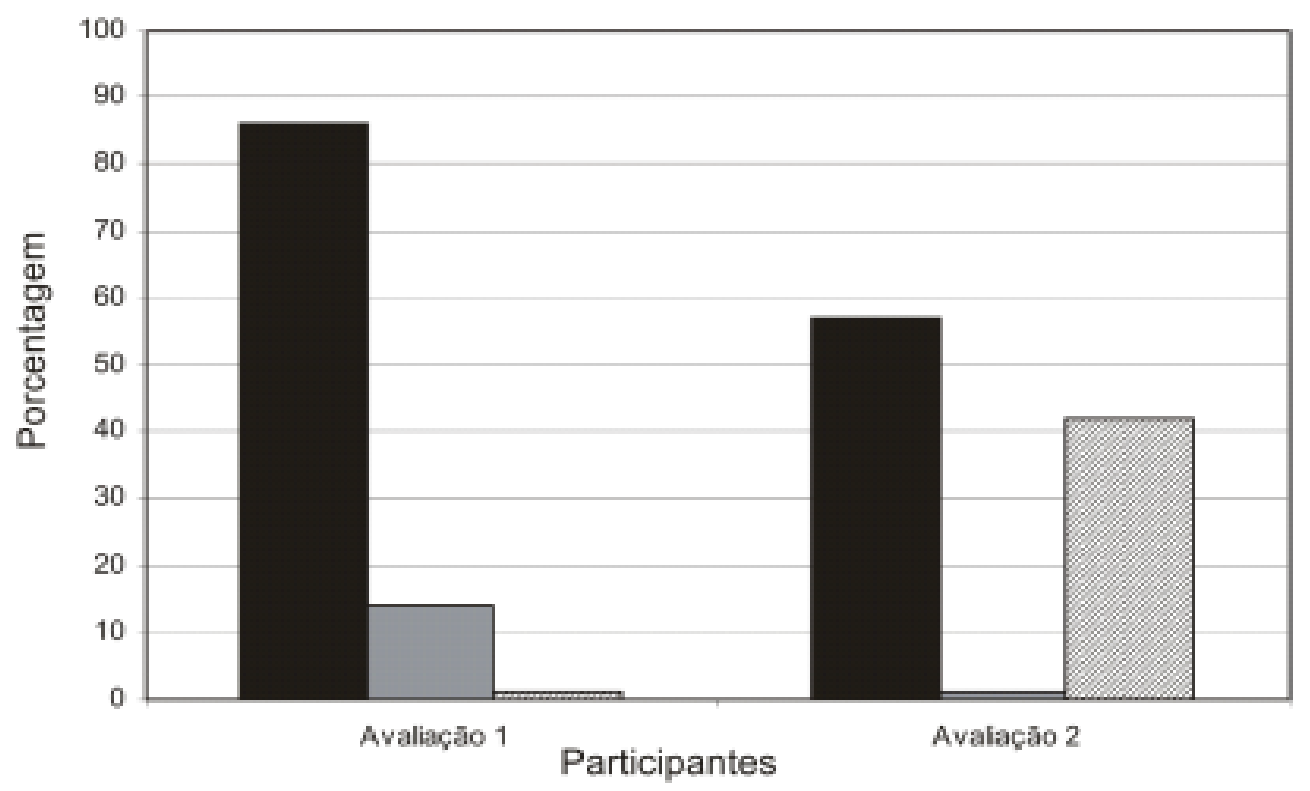

Figura 2 - Resultados relativos ao conceito de caligrafia para a primeira e segunda avaliação. As barras em preto representam o uso de unidades parecidas com letras, as em cinza o de letras e as hachuras o de escrita convencional.

Observa-se que $84 \%$ das crianças, na primeira avaliação, utilizavam apenas unidades parecidas com letras, contra $14 \%$ que eram capazes de grafar letras. Para a segunda avaliação verifica-se uma diminuição do número de crianças que utilizavam apenas unidades parecidas com letras ou as letras e um aumento das com uso da escrita convencional, indicando um avanço no processo de aquisição de leitura e escrita.

A mesma evolução pode ser acompanhada na Figura 3, em que para a primeira avaliação cerca de $29 \%$ das crianças não mostravam nenhuma evidência de princípio alfabético, 58\% tinham tal evidência e cerca de $14 \%$ um padrão consistente do uso do princípio alfabético. No entanto, na segunda avaliação é possível verificar que só $29 \%$ das crianças apresentavam evidência do uso do princípio alfabético e cerca de $72 \%$ um padrão consistente de seu uso. 


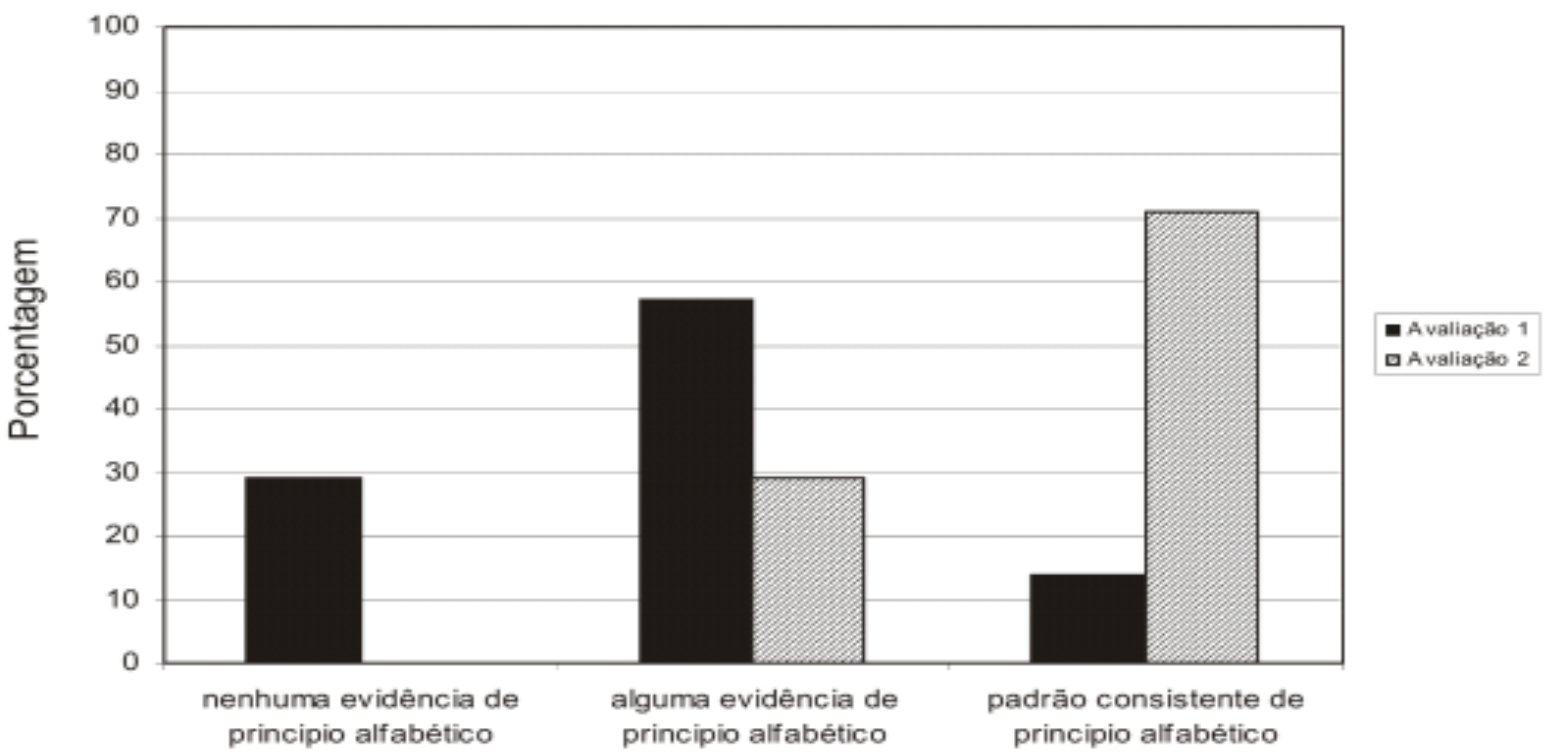

Figura 3 - Resultados relativos ao uso do principio alfabético para a primeira e segunda avaliação.

Os dados encontrados indicam que o processo de evolução de escrita descrito por Ferreiro e Teberosky (1986) é semelhante para crianças ouvintes e surdas; neste caso a interpretação da produção da escrita pode ser feita através dos aspectos construtivos, ou seja, pelo que ela quis representar e como chegou a produzir tal representação. A partir dessa interpretação, leva-se em consideração a evolução das conceituações sobre a escrita, com a identificação de três períodos fundamentais: $\mathrm{O}$ primeiro caracterizado pela busca de parâmetros de diferenciação entre as marcas gráficas figurativas e as não figurativas, o segundo pela construção de modos de diferenciação entre os encadeamentos das letras, baseando-se alternadamente em eixos de diferenciação quantitativos e qualitativos e o terceiro corresponde à fonetização da escrita.

Ainda segundo as autoras, a escrita não deve ser tomada como "um código de transcrição gráfica das unidades sonoras”, mas sim como um sistema de representação que evolui historicamente; então, o indivíduo precisa possuir uma base que lhe é conferida por meio do letramento emergente, sobre a leitura e a escrita.

No caso das crianças surdas esse terceiro período corresponderia à relação entre os grafemas e a datilologia em LIBRAS. Com base nos dados obtidos, pode-se observar que os participantes apresentaram desenvolvimento compatível com a idade cronológica de acordo com a literatura destinada para as crianças ouvintes.

Um terceiro conjunto de dados que pode ser observado no decorrer deste estudo diz respeito ao comportamento da professora em relação ao uso de livros paradidáticos em sala de aula. No início do estudo a professora não utilizava este importante recurso didático, no entanto ao final, após verificar que as crianças mostravam grande interesse pelo manuseio dos livros, ela criou um "cantinho de leitura", e passou a incentivar a leitura e a contar histórias em LIBRAS para as crianças pelo menos uma vez por semana.

Williams (2004) destaca a importância da leitura de livros de história na rotina escolar, sempre requisitando a participação da criança, contribuindo para a estruturação de forma independente da leitura e escrita convencional. Os dados encontrados corroboram a hipótese de que crianças surdas usuárias de LIBRAS têm interesse por livros conforme verificado por Rottenberg (2001).

Este estudo concluiu que crianças surdas, portadoras de perda auditiva neurossensorial bilate- 
ral de severa a profunda e/ou profunda expostas ao ensino formal da LIBRAS por pelo menos 16 meses, apresentam desenvolvimento satisfatório de Letramento emergente, adequado a sua idade cronológica, contudo há ainda muitas situações que podem ser melhoradas para facilitar e propiciar um desenvolvimento da leitura e da escrita, como uma participação mais efetiva da família no aprimoramento da aprendizagem de Língua de Sinais (LIBRAS), maiores recursos pedagógicos e melhor formação dos profissionais envolvidos no processo educacional.

\section{Referências}

Ciasca, S., Capellini, A. \& Tonelotto, B. (2003). Distúrbios específicos de aprendizagem. Em S. Ciasca (Org.), Distúrbios de aprendizagem: Proposta de avaliação interdisciplinar (pp 55-65). São Paulo: Casa do Psicólogo.

Ferreiro, E. \& Teberosky, A. (1986). Psicogênese da língua escrita. Porto Alegre: Artes Médicas.

Katims, D. S. (1994). Emergente of literacy in preschool children with disabilities. Learning Disability Quartely, 17, 58-69.

Katz, J. (1999). Tratado de Audiologia Clínica. São Paulo: Manole.

Limongi, S. C. O. (2003). Fonoaudiologia informação para formação-Linguagem: Desenvolvimento normal, alterações e distúrbios. Rio de Janeiro: Guanabara Koogan.

Luria, A. R. (1988). O desenvolvimento da escrita na criança. EM L. Vygotsky, A. R. Luria \& A.N. Leontiev (Orgs.), Linguagem, desenvolvimento e aprendizagem. (pp. 143-189). São Paulo: Ícone.

Quadros, R. M. \& Karnopp L. B. (2004). Língua Brasileira de Sinais. Porto Alegre: Artmed.

Rego, L. L. B.(1985). Descobrindo a língua escrita antes de aprender a ler: implicações pedagógicas. Revista Brasileira de Estudos Pedagógicos, 66(152), 5-27.

Rottenberg, C. J. (2001). A deaf Child Learns to Read: Americans Annals of the deaf, 146 (3), 270-275.
Sacks, O. (1998). Vendo vozes: uma viagem ao mundo dos surdos. São Paulo: Companhia das Letras.

Saint-Laurent, L.; Giasson, J. \& Couture, C. (1998). Emergent literacy and intellectual disabilities. Journal of Early Intervention, 21(3), 267-281.

Sulzby, E. (1985). Children's emergent reading of favorite storybooks: A developmental study. Reading Research Quarterly, 20, 448-458.

Sulzby, E. \& Teale, W. (1991). Emergent Literacy, In R. Barr; P. M. Kami; P. Mesenthol \& P.D. Peason (Eds.), Handbook of reading research, 727-757, New York: Longmam.

Willians, C. L. (1994). The language and literacy worlds of three profoundly deaf preschool children. Reading Research Quarterly 2, 125-155.

Williams, C. (2004). Emergent literacy of deaf children. Journal of Deaf studies and deaf Education 9(4), 352-365. 